\title{
Vitamin D deficiency and depression in obese adults: a comparative observational study
}

\author{
Leila Kamalzadeh $^{1}$ (D), Malihe Saghafi ${ }^{2}$, Seyede Salehe Mortazavi ${ }^{3}$ (D) and Atefeh Ghanbari Jolfaei ${ }^{2^{*}}$ (D)
}

\begin{abstract}
Background: Amongst the contributing factors of depression, vitamin D deficiency has increasingly drawn attention in recent years. This paper seeks to examine the association between serum vitamin D level and depression in patients with obesity.

Methods: In this comparative observational study, serum 25-hydroxyvitamin D [25(OH)D] levels were compared between obese individuals with depression $(n=174)$ and those without depression considering the effect of potential confounders. Participants were selected from males and females aged 18 to 60 years old visiting the outpatient obesity clinic of Rasoul-e Akram hospital, Tehran, Iran. The diagnosis of depressive disorder was made based on the Diagnostic and Statistical Manual of Mental Disorders (DSM-5) criteria. Additional clinical and laboratory data were collected from hospital electronic records. Mann-Whitney U test (nonparametric), Student's t-test (parametric), and Chi-squared test were used to analyze the differences between the two groups. To examine age and gender differences in the relationship between vitamin D deficiency and depression, stratified analyses were conducted by age and gender groups.
\end{abstract}

Results: The mean 25(OH) D levels were significantly different between depressed and non-depressed groups (20 \pm 15 vs. $27 \pm 13, P<0.001)$. Vitamin $D$ insufficiency/deficiency was detected in 78 and $67 \%$ of the depressed and nondepressed groups, respectively, which was significantly different $(P=0.03)$. The associations between depression and the serum $25(\mathrm{OH}) \mathrm{D}$ levels were observed regardless of gender and age. The overall average vitamin $D$ levels were not significantly different between total males and females ( $22 \pm 13$ vs. $23 \pm 14, P=0.49)$. The average level of vitamin $D$ was higher in the older age group (40-60 years) compared to younger participants (18-39years) (26 \pm 15 vs. $21 \pm 13$, $P=0.004)$.

Conclusion: The present study provides additional evidence for the hypothesis that low vitamin $D$ serum concentration is associated with depression in obese adults, and highlights the need for further research to determine whether this association is causal.

Keywords: Vitamin D deficiency, 25-hydroxyvitamin D, Obesity, BMI, Depression

\footnotetext{
* Correspondence: ghanbari.a@iums.ac.ir

${ }^{2}$ Minimally Invasive Surgery Research Center, Department of Psychiatry,

School of Medicine, Iran University of Medical Sciences, Tehran, Iran

Full list of author information is available at the end of the article
}

(c) The Author(s). 2021 Open Access This article is licensed under a Creative Commons Attribution 4.0 International License, which permits use, sharing, adaptation, distribution and reproduction in any medium or format, as long as you give appropriate credit to the original author(s) and the source, provide a link to the Creative Commons licence, and indicate if changes were made. The images or other third party material in this article are included in the article's Creative Commons licence, unless indicated otherwise in a credit line to the material. If material is not included in the article's Creative Commons licence and your intended use is not permitted by statutory regulation or exceeds the permitted use, you will need to obtain permission directly from the copyright holder. To view a copy of this licence, visit http://creativecommons.org/licenses/by/4.0/ The Creative Commons Public Domain Dedication waiver (http://creativecommons.org/publicdomain/zero/1.0/) applies to the data made available in this article, unless otherwise stated in a credit line to the data. 


\section{Introduction}

Obesity is increasingly recognized as a serious public health concern. More than 650 million people throughout the world suffer from overweight and obesity [1]. There is strong evidence to suggest that obesity is conjoint with several mental and physical problems [2]. Depression is one of the most prevalent psychiatric disorders reported in the obese population contributing to significant disability, mortality, and healthcare costs [3]. The exact mechanisms linking depression and obesity have not been established. Studies have shown multiplex interactions between biological, psychological, and environmental factors giving rise to the association between obesity and depression [4]. Amongst the contributing factors of depression, vitamin $\mathrm{D}$ deficiency has increasingly drawn attention in recent years [5].

Vitamin D, also known as cholecalciferol, is a unique neuro-steroid hormone that is vital for numerous brain functions. This hormone binds to receptors in numerous brain regions including the hippocampus and cingulate cortex, which are involved in the pathogenesis of depression and other mental illnesses [6]. Many clinical studies have found depression, anxiety and cognitive impairment to be associated with low serum levels of 25-hydroxyvitamin D $[25(\mathrm{OH}) \mathrm{D}]$, which is the major circulating form of vitamin $\mathrm{D}$, in average weight people [5-7]. Recent research has also provided evidence for antidepressant properties of vitamin $D$ supplementation $[8,9]$.

Strong evidence of aberrations in the vitamin Dendocrine system as well as low serum $25(\mathrm{OH}) \mathrm{D}$ levels have been seen in obese individuals $[10,11]$. It has been demonstrated that vitamin D deficiency is 35\% more likely in obese people compared to healthy-weight subjects [12]. Volumetric dilution of Vitamin $\mathrm{D}$ is the most plausible mechanism of low $25(\mathrm{OH}) \mathrm{D}$ in individuals with obesity [11]. Alternative mechanisms for lower $25(\mathrm{OH}) \mathrm{D}$ concentrations in patients with obesity include lower dietary consumption, decreased dermal synthesis, reduced intestinal absorption, altered metabolism, as well as less sunlight exposure due to lower physical activity [13].

Despite a biologically potential role of vitamin D in the development of depression, very few studies have investigated this association in overweight and obese subjects, with conflicting findings. While two studies indicated the benefits of vitamin D supplementation on depressive symptoms in obese adults [14, 15], a recent randomized trial presented contradictory results [16].

The discrepancy among these results has given rise to the need for further research. In this regard, this study seeks to examine the association between serum vitamin $\mathrm{D}$ level and depression in obese patients.

\section{Methods}

\section{Study design}

This comparative observational study was conducted at Rasoul-e Akram hospital, an Iran University of Medical Sciences affiliate located in Tehran, Iran.

\section{Study participants}

The study population consisted of males and females aged 18 to 60 years old visiting out-patient obesity clinic from April 2019 to October 2020. The participants were selected using convenience sampling. Based on the presence or absence of depressive symptoms, participants were categorized into two separate groups. The diagnosis of depressive disorder was made by expert psychiatrists using the Structured Clinical Interview for the Diagnostic and Statistical Manual of Mental Disorders (DSM-5) (SCID-5) [17]. All participants had documented serum 25-hydroxyvitamin D, thyroid-stimulating hormone (TSH), fasting blood sugar (FBS), and parathyroid hormone $(\mathrm{PTH})$ levels from their screening laboratory tests performed in the obesity clinic within 2 weeks before study enrollment. Additional clinical, anthropometric, and demographic data were collected from hospital electronic records. Eligibility criteria required patients to have a body mass index (BMI), calculated as weight $/$ height $^{2}\left(\mathrm{~kg} / \mathrm{m}^{2}\right)$, greater than or equal to $30 \mathrm{~kg} /$ $\mathrm{m}^{2}$, normal TSH, normal FBS, normal PTH level, no history of sleep apnea, neither past nor present substance use, no history of calcium supplement or vitamin D use for at least 1 month before study enrollment. Additional criteria for the non-depressed group included: not meeting criteria for another mental disorder and no history of psychiatric medication use. Patients with recent illnesses or incomplete medical records were excluded from the study.

\section{Measurements}

All laboratory evaluations were performed in the morning after an overnight fast using reliable assays. The serum $25(\mathrm{OH})$ D measurements were classified according to definitions established by the Endocrine Society: $30-100 \mathrm{ng} / \mathrm{ml}$ was considered normal, with insufficient $25(\mathrm{OH}) \mathrm{D}$ levels or hypovitaminosis D sub-grouped into two: vitamin D insufficiency $(20-29 \mathrm{ng} / \mathrm{ml})$ and vitamin D deficiency $(<20 \mathrm{ng} / \mathrm{ml})$ [18]. Considered laboratory reference ranges for other biochemical parameters were: TSH $(0.35-5.50 \mathrm{mIU} / \mathrm{L})$, FBS $(<100 \mathrm{mg} / \mathrm{dl})$, and PTH $(0-55 \mathrm{pg} / \mathrm{mL})$.

\section{Statistical analysis}

Categorical data were expressed as counts and percentages. Continuous variables were presented as mean and standard deviation (SD). The Statistical Package for Social Sciences, version 22 was used for all statistical analyses 
(SPSS Inc., Chicago, IL, USA). The normal distribution of the variables was examined using Kolmogorov- Smirnov test. Mann-Whitney U test (nonparametric), Student's ttest (parametric), and Chi-squared test were used to analyze the differences between two groups. To examine age and gender differences in the relationship between vitamin D deficiency and depression, stratified analyses were conducted by age and gender groups. A $p$-value of $<$ 0.05 was considered statistically significant.

\section{Results}

A total of 174 depressed patients and 173 non-depressed individuals were studied. The baseline characteristics of the participants are summarized in Table 1 . Statistically significant differences were observed among the two groups in terms of the ratio of females to males $(P<0.001)$ and age $(\mathrm{P}<0$.001), i.e., the depressed group had a significantly higher proportion of females $(92 \%$ vs. $75 \%)$ and a higher mean age than the non-depressed group ( $42 \pm 10$ vs. $37 \pm 10$ ). Moreover, vitamin D insufficiency/deficiency was detected in 77 and $67 \%$ of the depressed and non-depressed groups, respectively, which was significantly different $(P=0.03)$. The mean BMI was not significantly different between the groups $(P=0.05)$. The mean vitamin $\mathrm{D}$ levels were not significantly different between males and females $(22 \pm 13$ vs $23 \pm 14, P=0.49)$.

As can be seen from Table 2, the average vitamin D levels were significantly different between the depressed and non-depressed groups $(20 \pm 15$ vs. $27 \pm 13$, $P<0.001)$. Moreover, the results obtained from separate analyses on variable levels of gender, showed that the mean vitamin D level for the depressed men was significantly lower than non-depressed men $(17 \pm 14$ vs. $24 \pm$ $12, P=0.01)$. Similarly, depressed women had a notably lower mean vitamin $\mathrm{D}$ level compared to non-depressed women $(21 \pm 16$ vs. $27 \pm 13, \mathrm{P}<0.001)$. Therefore, the association between depression and the serum $25(\mathrm{OH})$ $D$ levels was observed regardless of gender.

As shown in Table 2, the mean serum vitamin D levels appear to be generally lower in men participating in this

Table 1 Baseline characteristics of the participants

\begin{tabular}{llll}
\hline Characteristic & $\begin{array}{l}\text { Depressed } \\
\boldsymbol{N = 1 7 4}\end{array}$ & $\begin{array}{l}\text { Non-depressed } \\
\boldsymbol{N = 1 7 3}\end{array}$ & $\boldsymbol{P}$ value \\
\hline Age (years) & $42 \pm 10$ & $37 \pm 10$ & $<0.001$ \\
18-39years, n (\%) & $72(40 \%)$ & $111(60 \%)$ & \\
40-60 years, n (\%) & $102(62 \%)$ & $62(38 \%)$ & \\
Female, n (\%) & $160(92 \%)$ & $130(75 \%)$ & $<0.001$ \\
BMI (Kg/m²) & $42 \pm 7$ & $43 \pm 7$ & 0.05 \\
Vitamin D status, n (\%) & & & 0.03 \\
$\quad$ Normal & $39(22 \%)$ & $56(32 \%)$ & \\
Insufficient/Deficient & $135(77 \%)$ & $117(67 \%)$ & \\
\hline
\end{tabular}

study compared to women. Nonetheless, these differences were not statistically significant. In other words, the mean vitamin $\mathrm{D}$ level in depressed men did not differ significantly from depressed women $(17 \pm 14$ vs. $21 \pm$ $16, P=0.28)$. Likewise, the mean vitamin $\mathrm{D}$ level in nondepressed men did not differ significantly from nondepressed women $(24 \pm 12$ vs. $27 \pm 13, P=0.10)$. The overall average vitamin $D$ levels were also not significantly different between total males and females $(22 \pm 13$ vs $23 \pm 14, P=0.49$ ).

Regarding age groups, our finding revealed that the mean vitamin D level for the depressed participants aged 18-39 years was significantly lower than that of nondepressed aged $18-39$ years $(16 \pm 13$ vs. $25 \pm 12, P<$ $0.001)$. In the same way, depressed participants aged 40 60 years had a notably lower mean vitamin D level compared to non-depressed aged $40-60$ ( $23 \pm 16$ vs. $29 \pm 14$, $P=0.03)$. Therefore, the association between depression and the serum $25(\mathrm{OH}) \mathrm{D}$ levels was observed regardless of age. The overall average vitamin D levels were also significantly different between age groups $18-39$ and $40-60$ (21 \pm 13 vs $26 \pm 15, P=0.004)$.

\section{Discussion}

The findings of the present study revealed that there is an association between low serum 25(OH) D levels and incident depression in obese patients. The relation between low levels of vitamin D and depression was already established in normal-weight individuals by past research [5-7]. However, relatively few studies have evaluated this relationship in obese adults, and results have been mixed. Consistent with our findings Jorde et al. [15] and Milaneschi et al. [4] found that a low serum level of vitamin D is a risk factor for depression and suggested that BMI plays an important mediating role in the association between vitamin $\mathrm{D}$ and depression. In the same vein, Irandoust et al. [14] demonstrated that both vitamin $\mathrm{D}$ supplementation and physical activity have a beneficial impact on depressive symptoms in obese females. Penckofer et al. [19] yielded comparable results in their study on women with type 2 diabetes. They demonstrated that vitamin D supplementation significantly ameliorated depression in the patients.

Multiple mechanisms are involved in the interaction between vitamin D deficiency, obesity, and depression. It has been proposed that an inverse relationship exists between vitamin D serum levels and BMI [20]. As was pointed out in the introduction to this paper, low serum $25(\mathrm{OH}) \mathrm{D}$ in obese patients can occur for many reasons including insufficient vitamin D consumption, increased fat or muscle mass, genotype variation in vitamin $\mathrm{D}$ binding proteins or enzymes responsible for vitamin D metabolism [11, 13]. On the other hand, vitamin D deficiency can increase the risk of developing depression, through several biological 
Table 2 Relationship between depression and the serum 25-hydroxyvitamin D levels totally and by Gender and Age

\begin{tabular}{|c|c|c|c|c|c|}
\hline & Non-D & & Depres & & $P$-value \\
\hline & $\overline{\text { Vitami }}$ & & Vitami & & \\
\hline & Mean & Standard Deviation & Mean & Standard Deviation & \\
\hline Total & 27 & 13 & 20 & 15 & $<0.001$ \\
\hline Gender & & & & & \\
\hline Male & 24 & 12 & 17 & 14 & 0.01 \\
\hline Female & 27 & 13 & 21 & 16 & $<0.001$ \\
\hline Age & & & & & \\
\hline $18-39$ & 25 & 12 & 16 & 13 & $<0.001$ \\
\hline $40-60$ & 29 & 14 & 23 & 16 & 0.03 \\
\hline
\end{tabular}

pathways including effects on immunomodulation, regulation of intracellular calcium stores, cellular signaling, modulation of the hypothalamic-pituitary-adrenal axis, intracellular calcium homeostasis, and production of neurotransmitters [6, 21]. Moreover, both obesity and vitamin $\mathrm{D}$ deficiency lead to chronic low-grade inflammation, which has been suggested to contribute to the development of depression $[11,22]$. At last, it is also possible that PTH levels contribute to the relation between vitamin D, BMI, and depression. Recent evidence suggests that both obesity and low vitamin D levels are accompanied by significantly higher PTH levels, and high PTH levels are related to depression [4].

Indeed, the possibility of reverse causality should also be noted. In other words, certain features associated with depression and obesity might have limited the vitamin D sources and increased the risk of vitamin D deficiency in the depressed participants of this study, as compared with the non-depressed group. For example, depressed individuals with obesity may avoid outdoor activity and sunlight exposure for long periods due to body image concerns, social withdrawal, anhedonia, particular personality traits, and pathological fatigue $[6,23]$. Furthermore, poor quality diet and metabolic derangements associated with obesity and depression can increase the demand for vitamin D (for restoring calcium homeostasis) and heighten the risk of vitamin D deficiency [24].

However, more recently, literature has emerged that offers contradictory findings on these associations. In contrast to the mentioned studies, in a randomized controlled study, Mousa et al. [16] showed that depressive symptoms in obese individuals were not associated with $25(\mathrm{OH})$ D concentrations, nor did improve by Vit D supplementation. Similarly, a recent clinical interventional cohort study revealed that vitamin D supplementation for 6 months had no significant impact on depressive symptoms, but could improve anxiety symptoms in depressed patients with vitamin D deficiency. The authors suggested that BMI is an important mediating factor between low serum $25(\mathrm{OH}) \mathrm{D}$ and anxiety symptoms [25].

Different findings may be attributed to the differences in the study population (different races, gender, and age groups), diverse methodology (different vitamin D supplementation doses and duration), and different baseline levels of serum $25(\mathrm{OH}) \mathrm{D}$ concentrations. Moreover, the mentioned studies applied self-reported psychiatric rating scales for evaluation of depression rather than a clinician-rated assessment and therefore were prone to multiple potential biases. In addition, some of the previous studies did not adjust for potential confounders, such as thyroid dysfunction, comorbid diabetes mellitus, sleep apnea, low physical activity, and substance use that may play a role in developing depression in the obese population [26].

As mentioned before, in this study depressed patients had significantly lower mean vitamin D levels than the non-depressed group; however, the distribution of gender groups in our study was quite imbalanced (overrepresentation of women). Considering biological and psychosocial differences between males and females, we also examined the relationship between vitamin D status and depression in men and women separately. In both genders, the mean vitamin D levels were significantly lower in the depressed group compared to nondepressed individuals. The finding is in the lines of earlier literature that found no significant interaction effect of gender on the association between vitamin D status and depression [6, 27]. Furthermore, in this study, the average vitamin D levels were not significantly different between male and female participants; however, it ought to be remarked that among the morbidly obese females, the risk of developing depression related to vitamin $\mathrm{D}$ deficiency could be higher than males owing to some psychosocial variables such as stigmatization, discrimination, poor self-esteem, social expectations, and gender-role attitudes resulting in further reduction of natural sources of vitamin D [28-30]. The results further demonstrated that vitamin D deficiency was associated with depression in both age groups. This 
association appeared to be even more robust in younger participants. A similar pattern of results has been obtained in other studies investigating the associations between vitamin $\mathrm{D}$ levels and depression across different age groups $[6,31,32]$. One unanticipated finding was that the average level of vitamin D was higher in the older age group compared to younger participants. Previous research has suggested that aging may contribute to vitamin $\mathrm{D}$ deficiency through several mechanisms including reduced renal production of $1,25(\mathrm{OH})_{2} \mathrm{D}$, decreased skin production of vitamin $\mathrm{D}$, and substrate deficiency of vitamin D [33]. It seems possible that our results are due to dietary supplement use which is common in older adults in Iran [32].

Several limitations to this study need to be acknowledged. First, the sample size was relatively small. Therefore, larger studies will be needed to confirm our observations. Second, the depressed and non-depressed groups were not matched based on age, gender, and season of collecting vitamin D. Recent evidence suggests that the circulating levels of $25(\mathrm{OH}) \mathrm{D}$ can be affected by acute illness, diurnal rhythm, and season of blood draw [34, 35]. However, it is noteworthy that participants were selected from the same hospital catchment area, and therefore had similar socioeconomic status. The key strength of this study is the exclusion of several potential confounders such as thyroid dysfunction, comorbid diabetes, hyperparathyroidism, and substance use which were not addressed by previous studies. Moreover, in the present study, the diagnosis of depression was based on standardized semi-structured interviews by expert psychiatrists rather than self-report rating scales.

\section{Conclusions}

In summary, the present study provides additional evidence for the hypothesis that low vitamin $\mathrm{D}$ serum concentration is associated with depression in obese adults, and highlights the need for further research to find out whether this association is causal.

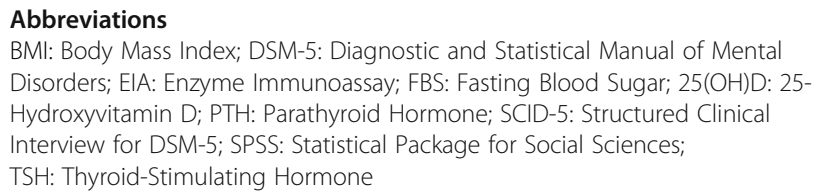

\section{Acknowledgments}

We would like to thank Dr. Vahid Saeedi for the contributions to this manuscript.

\section{Authors' contributions}

LK has drafted the work and substantively revised it. AGhJ has made substantial contributions to the conception of the work. MS was a major contributor in writing the manuscript. All authors read and approved the final manuscript.

\section{Funding}

This research received no specific grant from any funding agency in the public, commercial, or not-for-profit sectors.

\section{Availability of data and materials}

The datasets used and/or analyzed during the current study are available from the corresponding author on reasonable request.

\section{Declarations}

\section{Ethics approval and consent to participate}

The principles of the World Medical Association Declaration of Helsinki were adopted in the present study [36]. This research was approved by the independent ethics committee of Iran University of Medical Sciences (IR.IUMS.REC 1395.8721215026). All patients signed informed consent statements.

\section{Consent for publication}

Written informed consent was obtained from the patients for publication of this research and any accompanying images. A copy of the written consent is available for review by the Editor-in-Chief of this journal.

\section{Competing interests}

The authors declare that they have no competing interests.

\section{Author details}

${ }^{1}$ Mental Health Research Center, Psychosocial Health Research Institute, Department of Psychiatry, School of Medicine, Iran University of Medical Sciences, Tehran, Iran. ${ }^{2}$ Minimally Invasive Surgery Research Center, Department of Psychiatry, School of Medicine, Iran University of Medical Sciences, Tehran, Iran. ${ }^{3}$ School of Behavioral Sciences and Mental Health (Tehran Institute of Psychiatry), Iran University of Medical Sciences, Tehran, Iran

Received: 12 April 2021 Accepted: 8 November 2021

Published online: 30 November 2021

\section{References}

1. World Health Organization. Obesity and overweight [Internet]. 2020 [cited 2021 Jan 19]. Available from: https://www.who.int/news-room/fact-sheets/ detail/obesity-and-overweight

2. Mathieu L, Bitterlich N, Meissner F, von Wolff M, Poethig D, Stute P. Illness perception in overweight and obesity and impact on bio-functional age. Arch Gynecol Obstet [Internet]. 2018;298(2):415-26. Available from: https:// www.scopus.com/inward/record.uri?eid=2-s2.0-85049101223\&doi=10.1 007\%2Fs00404-018-4827-0\&partnerlD=40\&md5=c557ebda1a2e0c2016f0b2a 51678c676. https://doi.org/10.1007/s00404-018-4827-0.

3. Mulugeta A, Zhou A, Power C, Hyppönen E. Obesity and depressive symptoms in mid-life: a population-based cohort study. BMC psychiatry [Internet]. 2018;18(1):297. https://doi.org/10.1186/s12888-018-1877-6.

4. Milaneschi $Y$, Simmons WK, van Rossum EFC, Penninx BWJH. Depression and obesity: evidence of shared biological mechanisms. Mol psychiatry [Internet]. 2019;24(1):18-33. https://doi.org/10.1038/s41380-018-0017-5.

5. Okasha TA, Sabry WM, Hashim MA, Abdeen MS, Abdelhamid AM. Vitamin D Serum level in major depressive disorder and schizophrenia. Middle East Curr Psychiatry [Internet]. 2020;27(1):34. https://doi.org/10.1186/s43045-020-00043-y.

6. Menon V, Kar S, Suthar N, Nebhinani N. Vitamin D and depression: a critical appraisal of the evidence and future directions. Indian J Psychol Med [Internet]. 2020;42(1):11-21. Available from: https://www.scopus.com/inwa rd/record.uri?eid=2-s2.0-85078020152\&doi=10.4103\%2FIJPSYM.IJPSYM_1 60_19\&partnerlD=40\&md5=9694071d05c0826c66defd4405d4a0c9. https:// doi.org/10.4103/IJPSYM.IJPSYM_160_19.

7. Köhnke C, Herrmann M, Berger K. Associations of major depressive disorder and related clinical characteristics with 25-hydroxyvitamin D levels in middle-aged adults. Nutr Neurosci [Internet]. 2020; Available from: https:// www.scopus.com/inward/record.uri?eid=2-s2.0-85097370391\&doi=10.1 080\%2F1028415X.2020.1843892\&partnerlD=40\&md5=a640c9ed94a89a27a 0da2d8659c89bf2.

8. Alghamdi S, Alsulami N, Khoja S, Alsufiani H, Tayeb HO, Tarazi Fl. Vitamin D supplementation ameliorates severity of major depressive disorder. J Mol Neurosci [Internet]. 2020;70(2):230-5. Available from: https://www.scopus. 
com/inward/record.uri?eid=2-s2.0-85076270668\&doi=10.1007\%2Fs12031-01 9-01461-2\&partnerlD=40\&md5=36c9d55205189fd49e2509f0f6caedcf. https:// doi.org/10.1007/s12031-019-01461-2.

9. Kaviani M, Nikooyeh B, Zand H, Yaghmaei P, Neyestani TR. Effects of vitamin D supplementation on depression and some involved neurotransmitters. J Affect Disord [Internet]. 2020;269:28-35 Available from: https://www.scopus. com/inward/record.uri?eid=2-s2.0-85082682132\&doi=10.1016\%2Fj.jad.2020. 03.029\&partnerID $=40 \& m d 5=c 94 c 8 e 8 a 437624212 \mathrm{fe} 027 \mathrm{ccfa} 3 \mathrm{~b} 6179$.

10. Zakharova I, Klimov L, Kuryaninova V, Nikitina I, Malyavskaya S, Dolbnya S, et al. Vitamin D insufficiency in overweight and obese children and adolescents [Internet]. Front Endocrinol. 2019;10:103. https://doi.org/10.33 89/fendo.2019.00103.

11. Vranić L, Mikolašević I, Milić S. Vitamin D deficiency: consequence or cause of obesity? Medicina (Kaunas) [Internet]. 2019;55(9):541 Available from: https://pubmed.ncbi.nlm.nih.gov/31466220.

12. Pereira-Santos M, Costa PRF, Assis AMO, Santos CAST, Santos DB. Obesity and vitamin D deficiency: a systematic review and meta-analysis. Obes Rev [Internet]. 2015;16(4):341-9. https://doi.org/10.1111/obr.12239.

13. Duan $L$, Han L, Liu Q, Zhao Y, Wang L, Wang Y. Effects of vitamin D supplementation on general and central obesity: results from 20 randomized controlled trials involving apparently healthy populations. Ann Nutr Metab [Internet]. 2020;76(3):153-64. https://doi.org/10.1159/000507418.

14. Irandoust K, Taheri M. The effect of Vitamin D supplement and indoor Vs outdoor physical activity on depression of obese depressed women. Asian J Sports Med [Internet]. 2017;8(3) Available from: https://www.scopus.com/ inward/record.uri?eid=2-s2.0-85045020898\&doi=10.5812\%2Fasjsm.13311\&pa rtnerlD=40\&md5=eb06d0c58120daff9b71e75a785207b5.

15. Jorde R, Sneve M, Figenschau Y, Svartberg J, Waterloo K. Effects of vitamin $D$ supplementation on symptoms of depression in overweight and obese subjects: randomized double blind trial. J Intern Med [Internet]. 2008;264(6): 599-609. https://doi.org/10.1111/j.1365-2796.2008.02008.x.

16. Mousa A, Naderpoor N, de Courten MPJ, de Courten B. Vitamin D and symptoms of depression in overweight or obese adults: A cross-sectional study and randomized placebo-controlled trial. J Steroid Biochem Mol Biol [Internet]. 2018;177:200-8 Available from: https://www.scopus.com/inward/ record.uri?eid=2-s2.0-85027572947\&doi=10.1016\%2Fj.jsbmb.2017.08.002\&pa rtnerlD=40\&md5=9f2312e5481a2d7f14591ac703dca860.

17. First MB, Williams JBW, Karg RS, Spitzer RL. User's guide to structured clinical interview for Dsm-5 disorders (Scid-5-cv): clinician version 1st. The encyclopedia of clinical psychology. Washington, DC: American Psychiatric Association Publishing; 2015.

18. Holick MF, Binkley NC, Bischoff-Ferrari HA, Gordon CM, Hanley DA, Heaney $R P$, et al. Evaluation, treatment, and prevention of vitamin D deficiency: an endocrine society clinical practice guideline. J Clin Endocrinol Metab [Internet]. 2011;96(7):1911-30. https://doi.org/10.1210/jc.2011-0385.

19. Penckofer S, Byrn M, Adams W, Emanuele MA, Mumby P, Kouba J, et al. Vitamin D supplementation improves mood in women with type 2 diabetes. Campesi I, editor. J diabetes Res [Internet]. 2017;2017:8232863. https://doi.org/10.1155/2017/8232863.

20. Vigna L, Silvia Tirelli A, Grossi E, Turolo S, Tomaino L, Napolitano F, et al. Directional relationship between vitamin D status and prediabetes: a new approach from artificial neural network in a cohort of workers with overweight-obesity. J Am Coll Nutr [Internet]. 2019;38(8):681-92. Available from: https://www.scopus.com/inward/record.uri?eid=2-s2.0-8506514421 $8 \&$ doi $=10.1080 \% 2 F 07315724.2019 .1590249 \&$ partnerID $=40 \& m d 5=79 d 1$ d6bf679b3dc95821bc8ba8a7a4d1. https://doi.org/10.1080/07315724.2019.1 590249.

21. Lerner PP, Sharony L, Miodownik C. Association between mental disorders, cognitive disturbances and vitamin D serum level: current state. Clin Nutr ESPEN [Internet]. 2018;23:89-102. Available from: https://www.scopus.com/ inward/record.uri?eid=2-s2.0-85038824379\&doi=10.1016\%2Fj.cInesp.2017.11. 011\&partnerlD=40\&md5=71ef2ca0cbb7597fa895a6e9e367957b. https://doi. org/10.1016/j.clnesp.2017.11.011.

22. Abiri B, Vafa M. Effects of vitamin D and/or magnesium supplementation on mood, serum levels of BDNF, inflammatory biomarkers, and SIRT1 in obese women: a study protocol for a double-blind, randomized, placebocontrolled trial. Trials [Internet]. 2020;21(1):225. https://doi.org/10.1186/s13 063-020-4122-9

23. Kamalzadeh L, Nayeri V, Soraya S, Shariat SV, Alavi K. Determining TestRetest Reliability and Internal Consistency of the Persian Version of Personality Inventory For Diagnostic and Statistical Manual of Mental
Disorders-5th Edition (PID-5) Among Medical Students and Patients With Psychiatric Disorders. J Isfahan Med Sch [Internet]. 2016;34(393):901-7 Available from: https://www.sid.ir/en/Journal/NiewPaper.aspx? ID=528108.

24. Silveira EA, Cardoso CK de S, Moura L de ANE, Dos Santos Rodrigues AP, de Oliveira C. Serum and Dietary Vitamin D in Individuals with Class II and III Obesity: Prevalence and Association with Metabolic Syndrome. Nutrients [Internet]. 2021;13(7):2138 Available from: https://pubmed.ncbi.nlm.nih. gov/34206539.

25. Zhu C, Zhang Y, Wang T, Lin Y, Yu J, Xia Q, et al. Vitamin D supplementation improves anxiety but not depression symptoms in patients with vitamin D deficiency. Brain Behav [Internet]. 2020;10(11) Available from: https://www.scopus.com/inward/record.uri?eid=2-s2.0-85091 $006101 \&$ doi $=10.1002 \% 2 F b r b 3.1760 \&$ partnerlD $=40 \&$ md5=65e5ffbc6dfbc96a ce300a10c7363f10

26. González-Muniesa P, Mártinez-González M-A, Hu FB, Després J-P, Matsuzawa Y, Loos RJF, et al. Obesity. Nat Rev Dis Prim [Internet]. 2017;3(1):17034. https://doi.org/10.1038/nrdp.2017.34.

27. Mulugeta A, Lumsden A, Hyppönen E. Relationship between Serum 25(OH) D and Depression: Causal Evidence from a Bi-Directional Mendelian Randomization Study. Nutrients [Internet]. 2020;13(1):-109 Available from: https://pubmed.ncbi.nlm.nih.gov/33396887.

28. Weinberger N-A, Kersting A, Riedel-Heller SG, Luck-Sikorski C. The relationship between weight status and depressive symptoms in a population sample with obesity: the mediating role of appearance evaluation. Obes Facts [Internet]. 2018;11(6):514-23. https://doi.org/10.1159/ 000492000.

29. Shalaby AS, Sadik SAM, Mahmoud DAM. Psychiatric morbidities of female obesity before and after dieting: an Egyptian sample. Middle East Curr psychiatry [Internet]. 2020;27(1):62. https://doi.org/10.1186/s43045-02000068-3.

30. Kamalzadeh L, Salehi M, Rashedi V, Ahmadzad Asl M, Malakouti SK, Seddigh $R$, et al. Perceived burden of dementia care, clinical, psychological and demographic characteristics of patients and primary caregivers in Iran. Appl Neuropsychol [Internet]. 2020; Available from: https://www.scopus.com/inwa rd/record.uri?eid=2-s2.0-85088936414\&doi=10.1080\%2F23279095.2020.1 798960\&partnerlD=40\&md5=365f21 1a9ed86fd9f1648210e472ba92.

31. de Oliveira C, Hirani V, Biddulph JP. Associations Between Vitamin D Levels and Depressive Symptoms in Later Life: Evidence From the English Longitudinal Study of Ageing (ELSA). J Gerontol Ser A [Internet]. 2018; 73(10):1377-82. https://doi.org/10.1093/gerona/glx130.

32. Hovsepian S, Amini M, Aminorroaya A, Amini P, Iraj B. Prevalence of vitamin D deficiency among adult population of Isfahan City, Iran. J Health Popul Nutr [Internet]. $2011 ; 29(2): 149-55$. Available from: https://pubmed.ncbi.nlm. nih.gov/21608424. https://doi.org/10.3329/jhpn.v29i2.7857.

33. Gallagher JC. Vitamin D and aging. Endocrinol Metab Clin North Am [Internet]. 2013;42(2):319-32 Available from: https://pubmed.ncbi.nlm.nih. gov/23702404.

34. French CB, McDonnell SL, Vieth R. 25-Hydroxyvitamin D variability withinperson due to diurnal rhythm and illness: a case report. J Med Case Rep [Internet]. 2019;13(1):29 Available from: https://pubmed.ncbi.nlm.nih.gov/3 0712514.

35. Silva MC, Furlanetto TW. Does serum 25-hydroxyvitamin D decrease during acute-phase response? A systematic review. Nutr Res [Internet]. 2015;35(2): 91-6. Available from: https://www.sciencedirect.com/science/article/pii/SO2 71531714002875. https://doi.org/10.1016/j.nutres.2014.12.008.

36. World Medical Association. World medical association declaration of Helsinki: ethical principles for medical research involving human subjects. JAMA [Internet]. 2013;310(20):2191-4. https://doi.org/10.1001/jama.2013.281053.

\section{Publisher's Note}

Springer Nature remains neutral with regard to jurisdictional claims in published maps and institutional affiliations. 